\title{
Penggunaan Model Examples Non Examples untuk Meningkatkan Hasil Belajar pada Mata Pelajaran IPS Siswa SD
}

\author{
Karno \\ UPK Jatilawang Banyumas \\ Jl. Pramuka, Tunjung Wetan, Tunjung, Kec. Jatilawang, Kabupaten Banyumas, Jawa \\ Tengah \\ Email: bdmartono7@gmail.com
}

\begin{abstract}
Abstrak
Penelitian ini dilatari karena rendahnya hasil belajar IPS siswa kelas IV SD Negeri 2 Adisaran semester ganjil tahun pelajaran 2014/2015. Pelaksanaan penelitian dilakukan secara bertahap, yaitu melalui siklus I dan siklus II dengan menggunakan model examples non examples. Dari penelitian ini dapat diketahui hasil belajar IPS tentang komponen peta dan cara membaca peta yang diperoleh pada pembelajaran pra siklus yaitu dengan nilai terendah 40, nilai tertinggi 90, nilai rata-rata kelas 59,52 dengan ketuntasan belajar $19,05 \%$. Hasil belajar pada siklus I diperoleh nilai terendah 50, nilai tertinggi 100 dan ratarata kelas 76,66 dengan ketuntasan belajar 66,66\%. Adapun hasil belajar pada siklus II adalah nilai terendah 70, nilai tertinggi 100, nilai rata-rata kelas 89,52 dengan ketuntasan belajar $100 \%$. Kesimpulan dengan menggunakan model examples non examples dapat meningkatkan hasil belajar IPS pada siswa kelas IV khususnya tentang tentang komponen peta dan cara membaca peta. Peneliti berharap jika ada guru yang menggunakan model pembelajaran ini supaya meminimalisir kelemahan yang ada.
\end{abstract}

Kata kunci: examples non examples, hasil belajar, komponen peta.

\begin{abstract}
This research was based on the low learning outcomes of Social Studies students in grade IV SD Negeri 2 Adisaran odd semester 2014/2015 academic year. The research was carried out in stages, namely through cycle I and cycle II using the examples non examples model. From this research, it can be seen the results of social studies learning about the components of the map and how to read the maps obtained in pre-cycle learning, with the lowest value of 40 , the highest value of 90 , the average value of the class 59.52 with mastery learning $19.05 \%$. Learning outcomes in the first cycle obtained the lowest value of 50 , the highest value of 100 and an average grade of 76.66 with a mastery of learning $66.66 \%$. The learning outcomes in the second cycle are the lowest value of 70 , the highest value of 100 , the average grade of 89.52 with $100 \%$ completeness of learning. The conclusion by using the examples non examples model can improve social studies learning outcomes in class IV students especially about the map components and how to read maps. Researchers hope that if there are teachers who use this learning model in order to minimize existing weaknesses.
\end{abstract}

Keywords: examples non examples, learning outcomes, map components.

\section{PENDAHULUAN}

Penyusunan PTK ini merupakan upaya perbaikan pembelajaran pada kelas IV di SD Negeri 2 Adisara UPK Jatilawang Kabupaten Banyumas pada pembelajaran Ilmu 
Pengetahuan Sosial (IPS) tentang komponen peta dan cara membaca peta. Kriteria Ketuntasan Minimal (KKM) pada mata pelajaran ini adalah $\geq 70,00$. Penelitian ini dilaksanakan karena setelah melakukan pembelajaran IPS tentang komponen peta dan cara membaca peta, peneliti merasa kecewa dengan hasil belajar siswa. Hasil belajar siswa sangat jauh dari yang peneliti harapkan. Siswa yang memperoleh nilai $\geq$ KKM hanya $19,05 \%$ atau 4 siswa dari 21 siswa, dan yang masih $\leq$ KKM adalah sejumlah 80,95\% atau 17 siswa dari 21 siswa. Berdasarkan dari kekecewaan terhadap hasil belajar tersebut, peneliti mencoba menganalisis penyebab dari rendahnya hasil belajar siswa. Demi terciptanya peningkatan hasil belajar siswa, maka peneliti akan melaksanakan upaya perbaikan pembelajaran melaui pelaksanaan PTK.

Dalam pelaksanaan PTK ini, model pembelajaran yang digunakan adalah menggunakan model examples non examples.Strategi yang diterapkan dari model ini bertujuan untuk mempersiapkan siswa secara cepat dengan menggunakan dua hal yang terdiri dari examples non examples dari suatu definisi konsep yang ada, dan meminta siswa untuk mengklasifikasikan keduanya sesuai dengan konsep yang ada. Examples memberikan gambaran akan sesuatu yang menjadi contoh akan suatu materi yang sedang dibahas, sedangkan non examples memberikan gambaran akan sesuatu yang bukanlah contoh dari suatu materi yang sedang dibahas.

Tujuan penulisan ini adalah cara maksimal guru dalam menggunakan model examples non examples untuk meningkatkan hasil belajar pada mata pelajaran IPS tentang komponen peta dan cara membaca peta bagi siswa kelas IV SD Negeri 3 Sudagaran. Tujuan khusus dari pelaksanaan penelitian ini adalah meningkatkan hasil belajar siswa pada mata pelajaran IPS tentang komponen peta dan cara membaca peta bagi siswa kelas IV SD Negeri 3 Sudagaran pada semester ganjil tahun pelajaran 2014/2015.

Ilmu Pengetahuan Sosial (IPS) adalah bidang studi yang mempelajari, menelaah, dan menganalisis gejal dan masalah sosial di masyarakat ditinjau dari berbagai aspek kehidupan secara terpadu. Sifat IPS sama dengan studi sosial yaitu praktis, interdisipliner dan diajarkan mulai dari pendidikan dasar sampai perguruan tinggi. Menurut pendapat A.Sanusi (1971: 1.25) pengertian studi sosial tidak selalu bertaraf akademik-universitas, bahkan dapat merupakan bahan-bahan pelajaran bagi anak didik sejak pendidikan dasar dan dapat berfungsi sebagai pengantar bagi lanjutan kepada disiplin-disiplin ilmu sosial. Studi sosial bersifat interdisipliner, dengan menetapkan pilihan judul atau masalah-masalah tertentu berdasarkan suatu rangka referensi dan meninjau dari beberapa sudut pandang $\underline{\text { sambil mencari logika dari hubungan-hubungan yang ada satu sama lainnya. Sedangkan }}$ 
menurut Jarolimek (1977: 1.25) studi sosial lebih bersifat praktis yaitu memberikan kemampuan kepada anak didik dalam mengelola dan memanfaatkan kekuatan-kekuatan fisik dan sosial dalam menciptakan kehidupan yang serasi.Studi sosial ini juga mempersiapkan anak didik untuk mampu memecahkan masalah sosial dan memiliki keyakinan akan kehidupan masa datang. Ruang lingkup mata pelajar IPS SD meliputi aspek-aspek sebagai berikut: Manusia, tempat dan lingkungan. Waktu, keberlanjutan dan perubahan.Sistem sosial dan budaya. Perilaku ekonomi dan kesejahteraan. Model pembelajaran examples non examples atau juga biasa di sebut examples and non examples merupakan model pembelajaran yang menggunakan gambar sebagai media pembelajaran. Penggunaan media gambar ini disusun dan dirancang agar anak dapat menganalisis gambar tersebut menjadi sebuah bentuk diskripsi singkat mengenai apa yang ada didalam gambar. Penggunaan model pembelajaran examples non examples ini lebih menekankan pada konteks analisis siswa.

Langkah-Langkah Model Examples Non Examples Guru mempersiapkan gambargambar sesuai dengan tujuan pembelajaran.Guru menempelkan gambar di papan atau ditayangkan lewat OHP.Guru memberi petunjuk dan memberi kesempatan kepada siswa untuk memperhatikan / menganalisa gambar.Melalui diskusi kelompok 2-3 orang siswa, hasil diskusi dari analisa gambar tersebut dicatat pada kertas.Tiap kelompok diberi kesempatan membacakan hasil diskusinya. Mulai dari komentar / hasil diskusi siswa, guru mulai menjelaskan materi sesuai tujuan yang ingin dicapai.Kesimpulan.

\section{METODE PENELITIAN}

Penelitian tindakan kelas ini atas dasar beberapa alasan, antara lain. Pada siswa kelas IV SD Negeri 3 Sudagaran dalam menyelesaikan soal uraian mata pelajaran IPS tentang komponen peta dan cara membaca peta, masih sangat jauh dari harapan ketuntasan. Siswa yang memperoleh nilai $\geq$ KKM hanya ada 4 siswa dari 21 siswa atau 19,05\%, dan yang masih $\leq$ KKM adalah sejumlah 17 siswa dari 21 siswa atau 80,95\%. Siswa yang mengalami kesulitan dalam menyelesaikan soal tersebut karena siswa tidak memperhatikan penjelasan guru tentang materi yang disampaikan, bahkan banyak sekali siswa yang bergurau dan bermain sendiri. Setelah peneliti analisis, hal semacam ini terjadi karena dalam proses penyampaian materi, guru selalu menggunakan model pembelajaran yang membosankan bahkan tidak menggunakan alat peraga sebagai media pembelajaran.

Strategi yang diterapkan dari model ini bertujuan untuk mempersiapkan siswa secara cepat dengan menggunakan dua hal yang terdiri dari ekxample non exsample dari 
suatu definisi konsep yang ada, dan meminta siswa untuk mengklasifikasikan keduanya sesuai dengan konsep yang ada. Example memberikan gambaran akan sesuatu yang menjadi contoh akan suatu materi yang sedang dibahas, sedangkan non-example memberikan gambaran akan sesuatu yang bukanlah contoh dari suatu materi yang sedang dibahas.

\section{HASIL DAN PEMBAHASAN}

Setelah dilaksanakan perbaikan pembelajaran pada sikus I telah terjadi peningkatan walaupun belum secara maksimal, hal ini dapat dilihat berdasarkan data hasil perencanaan, pelaksanaan, pengamatan dan refleksi di bawah ini:

Tabel 2 Hasil Belajar Siswa pada Siklus I

\begin{tabular}{|c|c|c|c|c|c|}
\hline \multirow[t]{2}{*}{ No } & \multirow[t]{2}{*}{ Nama Siswa } & \multicolumn{4}{|c|}{ Siklus I } \\
\hline & & Nilai & Naik & Belum Naik & Ket \\
\hline 1 & Agus Raharjo & 90 & $\sqrt{ }$ & & $\mathrm{T}$ \\
\hline 2 & Agus Dimastirto & 80 & $\sqrt{ }$ & & $\mathrm{T}$ \\
\hline 3 & Bambang S & 100 & $\sqrt{ }$ & & BT \\
\hline 4 & Budi Rahadjo & 50 & $\sqrt{ }$ & & $\mathrm{T}$ \\
\hline 5 & Dulah Kambali & 100 & $\sqrt{ }$ & & $\mathrm{T}$ \\
\hline 6 & Dedi Hananto & 100 & $\sqrt{ }$ & & $\mathrm{T}$ \\
\hline 7 & Dedi Muhtadi & 80 & $\sqrt{ }$ & & $\mathrm{T}$ \\
\hline 8 & Endang Wahyuni & 80 & $\sqrt{ }$ & & $\mathrm{T}$ \\
\hline 9 & Eni Wahyuningsih & 70 & $\sqrt{ }$ & & $\mathrm{T}$ \\
\hline 10 & Fadilah & 60 & $\sqrt{ }$ & & BT \\
\hline 11 & Farhat & 50 & $\sqrt{ }$ & & BT \\
\hline 12 & Gading Minulya & 70 & $\sqrt{ }$ & & $\mathrm{T}$ \\
\hline 13 & Gilang rahmadi & 60 & $\sqrt{ }$ & & BT \\
\hline 14 & Farida & 100 & $\sqrt{ }$ & & $\mathrm{T}$ \\
\hline 15 & Yusuf Madusar & 100 & $\sqrt{ }$ & & $\mathrm{T}$ \\
\hline 16 & Kiki Waluyo & 60 & $\sqrt{ }$ & & BT \\
\hline 17 & Tanzila Faiza & 60 & $\sqrt{ }$ & & BT \\
\hline 18 & Catleya Fathchi & 80 & $\sqrt{ }$ & & $\mathrm{T}$ \\
\hline 19 & Yoga Satria & 60 & $\sqrt{ }$ & & $\mathrm{BT}$ \\
\hline 20 & Navida Satria & 70 & $\sqrt{ }$ & & $\mathrm{T}$ \\
\hline 21 & Anugrah Syahril & 90 & $\sqrt{ }$ & & $\mathrm{T}$ \\
\hline & Jumlah & 1.610 & & & \\
\hline & Rata-rata & 76,66 & & & \\
\hline & Jumlah tuntas & 14 & & & \\
\hline & Persentase tuntas & $66,66 \%$ & & & \\
\hline & Jumlah tidak tuntas & 7 & & & \\
\hline & Persentase tidak tuntas & $33,34 \%$ & & & \\
\hline
\end{tabular}


Berdasarkan tabel dapat dilihat bahwa hasil belajar siswa pada siklus I, yaitu siswa yang mencapai ketuntasan adalah sebanyak 14 siswa dari 21 siswa atau sebesar 66,66\%. Sedangkan siswa yang belum tuntas sejumlah 7 siswa dari 21 siswa atau sebesar 33,34\% dengan rata-rata kelas 76,66.

\section{Deskripsi Hasil Penelitian Siklus II}

Ketika melaksanakan perbaikan pembelajaran pada siklus II, peneliti akan berusaha semaksimal mungkin untuk melakukan perbaikan-perbaikan tindakan berdasarkan siklus I. pada siklus II adalah dengan cara memperbanyak gambar peta, ukuran peta yang lebih besar dan gambar simbol-simbol peta yang lebih jelas serta melakukan penekanan pada kunci-kunci materi agar siswa akan lebih fokus. PAda tahap 2 siswa kelas IV SD Negeri 3 Sudagaran pada pembelajran perbaikan siklus II dalam menyelesaikan soal uraian mata pelajaran IPS tentang komponen peta dan cara membaca peta sudah meningkat secara maksimal. Siswa yang memperoleh nilai $\geq$ KKM sudah mencapai $100 \%$ atau 21 siswa dari 21 siswa yaitu tergambar pada warna biru, dan yang masih $\leq \mathrm{KKM}$ adalah sejumlah $0 \%$ atau 0 siswa dari 21 siswa yaitu tergambar dari warna merah yang sudah tidak muncul. Berdasarkan data diatas maka dapat disimpulkan bahwa pembelajaran IPS tentang komponen peta dan cara membaca peta sudah berhasil maksimal yaitu telah mencapai 100 $\%$.

\section{Pembahasan Hasil Penelitian Perbaikan Pembelajaran}

Pada pembelajaran awal, hasil belajar siswa kelas komponen peta dan cara membaca peta sangatlah belum memuaskan. Setelah dilakukan analisis dan perbaikan pembelajaran pada siklus I dan II, hasil penelitian ini dapat diuraikan sebagai berikut:berdasarkan hasil pengamatan dan pengumpulan data dari pelaksanaan perbaikan pembelajaran baik pada prasiklus, siklus I maupun pada Siklus II dapat dilihat pada Tabel 4 di bawah ini.

Tabel 4 Rekapitulasi Hasil Belajar Siswa pada Pembelajaran

\begin{tabular}{|c|l|c|c|c|c|}
\hline \multirow{2}{*}{ No } & \multirow{2}{*}{ Kegiatan } & \multicolumn{2}{|c|}{ Siswa Tuntas } & \multicolumn{2}{c|}{ Siswa Belum Tuntas } \\
\cline { 3 - 6 } & & Frekuensi & $\%$ & Frekuensi & $\%$ \\
\hline 1. & Studi Awal & 4 & 19,05 & 17 & 80,95 \\
2. & Siklus I & 14 & 66,66 & 7 & 33,34 \\
3. & Siklus II & 21 & 100 & 0 & 0 \\
\hline
\end{tabular}

Dari Tabel 4 tentang rekapitulasi hasil belajar siswa pada pembelajaran prasiklus, siklus I dan siklus II dapat diperoleh keterangan sebagai berikut: 
a. Pada prasiklus, jumlah siswa yang tuntas ada 4 siswa dari 21 siswa dengan persentase $19,05 \%$ dan siswa yang belum tuntas ada 17 siswa dari 21 siswa dengan persentase $80,95 \%$.

b. Pada siklus I, jumlah siswa yang tuntas ada 14 siswa dari 21 siswa dengan persentase $66,66 \%$ dan siswa yang belum tuntas ada 7 siswa dari 21 siswa dengan persentase $33,34 \%$.

c. Pada siklus II, jumlah siswa yang tuntas ada 21 siswa dari 21 siswa dengan persentase Dari Gambar 4.7 Grafik tentang rekapitulasi hasil belajar siswa dapat disimpulkan bahwa pada prasiklus, jumlah siswa yang tuntas ada 4 siswa dari 21 siswa dengan persentase $19,05 \%$. Sedangkan pada siklus I, jumlah siswa yang tuntas ada 14 siswa dari 21 siswa dengan persentase $66,66 \%$. Kemudian pada siklus II, jumlah siswa yang tuntas ada 21 siswa dari 21 siswa dengan persentase $100 \%$.

Dari Tabel 4. tentang rekapitulasi hasil belajar siswa pada pembelajaran prasiklus, siklus I dan siklus II sudah ada penurunan pada siswa yang belum tuntas dalam pembelajaran, hal ini dapat dilihat pada grafik berikut:

Gambar 4. Grafik Penurunan Ketidaktuntasan Siswa

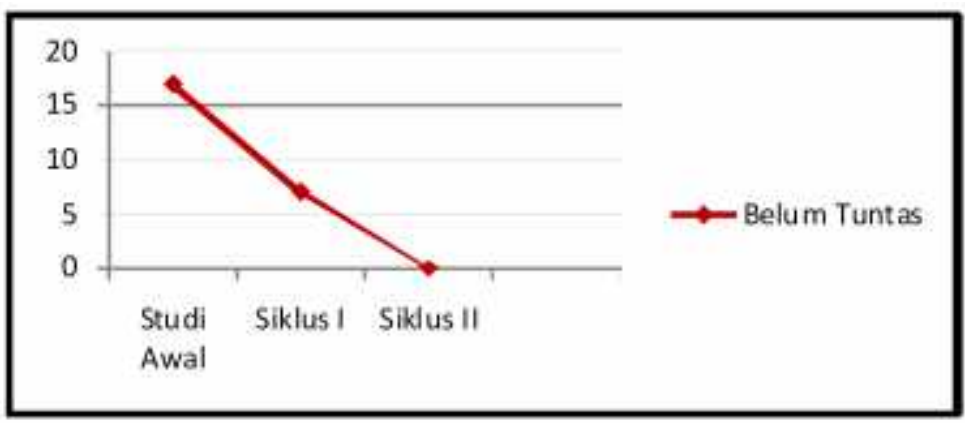

Dari Gambar 4 di atas jumlah siswa yang belum tuntas ada 17 siswa dari 21 siswa dengan persentase $80,95 \%$. Sedangkan pada siklus I, jumlah siswa yang belum tuntas ada 7 siswa dari 21 siswa dengan persentase 33,34\%. Kemudian pada siklus II, jumlah siswa yang belum tuntas ada 0 siswa dari 21 siswa dengan persentase 0\%. Berdasarkan hasil pengamatan dari pelaksanaan perbaikan pembelajaran baik pada prasiklus, siklus I maupun pada Siklus II tentang hasil evaluasi tes formatif dapat dilihat pada Tabel 5. di bawah ini.

Tabel 5 Rekapitulasi Hasil Evaluasi Siswa pada Pembelajaran

\begin{tabular}{|c|c|c|c|c|c|c|}
\hline \multirow{2}{*}{ No. } & \multirow{2}{*}{ Kegiatan } & \multirow{2}{*}{ Rata-rata } & \multicolumn{2}{c|}{ Siswa Tuntas Belajar } & \multicolumn{2}{c|}{ Siswa Belum Tuntas Belajar } \\
\cline { 4 - 7 } & & & Frekuensi & $\%$ & Frekuensi & $\%$ \\
\hline 1. & Studi Awal & 59,52 & 4 & 19,05 & 17 & 80,95 \\
2. & Siklus I & 76,66 & 14 & 66,66 & 7 & 33,34 \\
3. & Siklus II & 88,52 & 21 & 100 & 0 & 0 \\
\hline
\end{tabular}


Dari Tabel 5 di atas tentang rekapitulasi hasil belajar siswa pada pembelajaran sudah ada peningkatan secara maksimal, hal ini dapat dilihat pada grafik berikut:

Gambar 5 Diagram Batang Ketuntasan Hasil Belajar Siswa

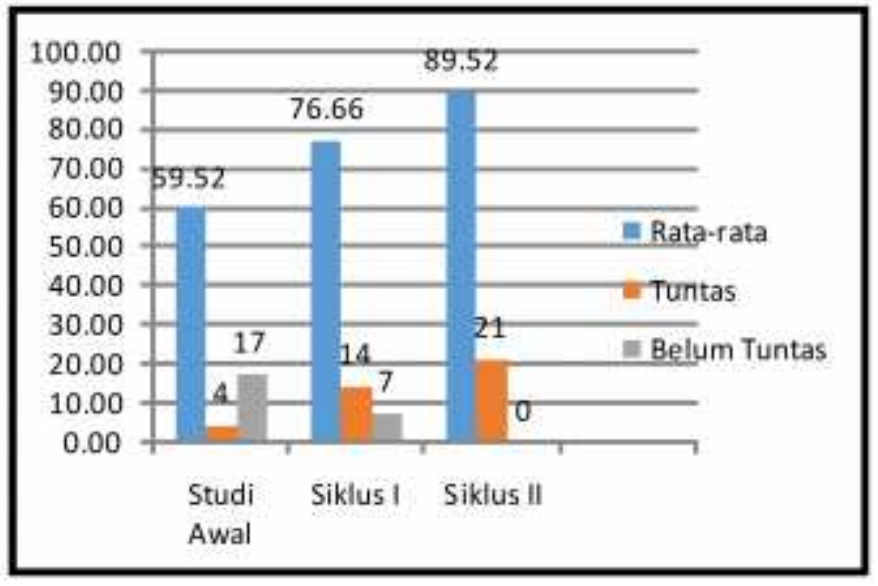

\section{KESIMPULAN}

Dengan model examples non examples dapat disimpulkan bahwa hasil belajar siswa SD Negeri 3 Sudagaran di kelas IV pada mata pelajaran IPS tentang materi komponen peta dan cara membaca peta dengan menggunakan model examples non examples dapat meningkatkan hasil belajar siswa. Hasil belajar siswa meningkat 47,61\% dari kegiatan pembelajaran prasiklus hingga siklus I. Peningkatan hasil belajar siswa ini terbukti pada pembelajaran prasiklus hanya 4 siswa atau 19,05\% yang tuntas $\geq$ KKM dan ada 17 siswa atau $80,95 \%$ yang belum tuntas $\leq \mathrm{KKM}$. Setelah dilakukan perbaikan pembelajaran pada siklus I, hasil belajar siswa semakin meningkat yaitu pada siklus I ada 14 siswa atau 66,66 $\%$ yang tuntas $\geq$ KKM dan ada 7 siswa atau 33,34\% yang belum tuntas $\leq$ KKM.

Kemudian pada siklus II perbaikan pembelajaran melalui penelitian tindakan kelas di SD Negeri 3 Sudagaran Kelas IV pada mata pelajaran IPS tentang komponen peta dan cara membaca peta dengan menggunakan model examples non examples hasil pembelajarnnya telah berhasil. Hasil belajar siswa meningkat 33,34\% dari kegiatan pembelajaran siklus I hingga siklus II. Peningkatan hasil belajar siswa ini terbukti pada pembelajaran siklus I hanya 14 siswa atau 66,66 \% yang tuntas $\geq$ KKM dan ada 7 siswa atau $33,34 \%$ yang belum tuntas $\leq \mathrm{KKM}$. Setelah dilakukan perbaikan pembelajaran pada siklus II, hasil belajar siswa semakin meningkat yaitu pada siklus II ada 21 siswa atau 100 $\%$ yang tuntas $\geq \mathrm{KKM}$ dan ada 0 siswa atau $0 \%$ yang belum tuntas $\leq \mathrm{KKM}$. Berdasarkan hasil belajar pada siklus II, maka peneliti menganggap kegiatan perbaikan pembelajaran melalui penelitian tindakan kelas dalam meningkatkan hasil belajar tentang komponen peta 
dan cara membaca peta pada mata pelajaran IPS kelas IV di SD Negeri 3 Sudagaran Tahun Pelajaran 2014/2015 sudah berhasil secara maksimal dan dinyatakan berakhir.

\section{SARAN}

Perlu dilakukan penelitian tindakan kelas yang berkaitan tentang metode pembelajaran inovatif

\section{DAFTAR PUSTAKA}

Brownell,William. (2012). Pendidikan Matematika I. Tangerang Selatan. Penerbit: Universitas Terbuka.

Gestalt. (2011). Strategi Pembelajaran. Jakarta. Pusat Penerbit: Universitas Terbuka.

Jarolimek. (2011). Pendidikan IPS di SD. Jakarta. Penerbit: Universitas Terbuka.

R. Hilgard, Ernest. (2011). Strategi Pembelajaran. Jakarta. Pusat Penerbit: Universitas Terbuka.

Romizoswki. (2011). Strategi Pembelajaran. Jakarta. Pusat Penerbit: Universitas Terbuka

Sanusi A. (2011). Pendidikan IPS di SD. Jakarta. Penerbit: Universitas Terbuka. 